\title{
Waste Management by Biological Approach Employing Natural Substrates and Microbial Agents for the Remediation of Dyes' Wastewater
}

\author{
Divakar Dahiya and Poonam Singh Nigam * \\ Biomedical Sciences Research Institute, Ulster University, Coleraine BT52 1SA, Northern Ireland, UK; \\ ddahiya@hotmail.co.uk \\ * Correspondence: p.singh@ulster.ac.uk
}

Received: 13 March 2020; Accepted: 20 April 2020; Published: 24 April 2020

\begin{abstract}
This article aims to provide information on two aspects: firstly, waste management of residual biological agro-industrial materials generated from agriculture, and secondly, for the sustainable remediation of textile wastewater. Annually, huge amounts of solid renewable biomass materials are generated worldwide from agricultural and farming sectors. The generation of these vast amounts of solid wastes could be utilised as a valuable and renewable natural resource for various applications. The goal of promoting sustainable development has increased the interest in recycling wastes economically and in an eco-friendly way. This article reviews the published research on this topic and discusses the usage of these solid substrates in the remediation of a major environmental component, textile dye-contaminated water. The purpose of this article is to discuss an integrated and cross-disciplinary approach to sustainable solid and liquid waste management and remediation of environmental components and to report the biological approaches and their efficiency in a chemical-free and economically viable bioremediation process for large volumes of dye-contaminated water resources.
\end{abstract}

Keywords: agro wastes; waste management; waste remediation; bioremediation; textile effluent; dyes; agricultural residues

\section{Environmental Pollution Due to Textile Wastewater}

The protection of the aquatic environment and life by regulation guidelines of water pollution has become of increasing importance. Although the release of dyes containing coloured water into the environment only contributes a small proportion of water pollution, when compared to other chemical-pollutants, dyes are visible due to their colour even if present in very small quantities. Strict legislation is forcing textile industries to dispose of their waste-effluent after treatment to a required standard. Dyes are used mainly in textile manufacturing to dye fabrics in different colours. The dyes are soluble compounds and are commonly classified under groups of reactive, direct, basic, and acid dyes. The annual production of these dyes is estimated at over $7 \times 10^{5}$ tons worldwide, whereas approximately $10-15 \%$ of dye production is wasted in the water bodies during the various processes in dye manufacturing and dyeing in multiple industries.

Wastewater generated from the textile industry is a mixture of a variety of polluting materials, including synthetic dyes and other chemicals used in washing and colour-stripping of over or uneven dyed cotton and during the finishing of coloured fabric. These dyes are recalcitrant to microbial degradation because they contain substitutions such as azo, nitro, or sulpho groups.

Several types of synthetic dyes as colour-contributing chemicals are being used in textile companies, although in smaller quantities. The synthetic dyes not only affect the aesthetic quality of water sources due to their colour, but also increase biochemical oxygen demand (BOD) and chemical oxygen demand (COD), 
inhibiting the rate of photosynthesis and plant growth. Dye-contaminated water, if used for irrigation, might enter our food chain, which in the long term will result in recalcitrance and bioaccumulation, and in the development of toxicity, mutagenicity, and carcinogenicity in living systems. The presence of dyes contributes a small fraction of the total organic-load present in wastewater; however, if disposed of as untreated wastewater, their colour in water sources makes them visually unacceptable [1]. Wastewater discharge from textile and dyes manufacturing companies to water bodies and water treatment systems disturbs the ecosystem. It causes health concerns to aquatic life, flora, and fauna; in return, humans are also affected by consuming seafood sourced from such contaminated water. This whole cycle of health concern is alarming to environment-regulatory authorities. Removal of colour from effluents has become of global scientific interest, which is evident from several scientific reports published on this subject [2-4].

In the last few decades, many physico-chemical techniques for the decolourisation of textile wastewater have been reported, but only a few are practically possible for use by the textile industries. Their implementation is not profitable due to their high cost, less efficiency, and inapplicability of methods to treat a wide range of synthetic dyes present in large volumes of water. Conventionally, the removal of dyes from wastewater has been practiced by physical and chemical methods. Some commonly used methods are adsorption, coagulation, precipitation, filtration, oxidation, and ion-exchange affinity-adsorption [5], which have been used for the remediation of textile effluent. The process of adsorption appears to offer the best prospects over all the other treatments. These systems are mostly expensive, and although the concentration of dyes is either reduced or removed from wastewater, after the treatment process, the resultant sludge creates another problem in terms of their safe and economical disposal.

Microbial degradation of several azo and anthraquinone types of dyes has been previously reported. Employing microbial systems means, bacteria worked only under anaerobic conditions and the azo dyes were reduced to their corresponding amines and which were difficult to completely break down aerobically [2-4]. Therefore, it is important to find alternative treatments for removing dyes from large volumes of textile effluents and particularly those methods that are environment-friendly and economical. Robinson et al. [4] have critically reviewed several physical and chemical processes used by other researchers and concluded that the use of a practical and cheaper alternative for the decolourisation, such as biological or combination systems, could only be applicable on a large-scale.

In the following sections, we review information published on various options for the treatment of dye-contaminated water using biological materials and systems.

\section{Use of Agricultural Residues as Low-Cost Sorbents in Colour Removal}

Nigam et al. [6] have investigated in detail a few non-chemical methods for textile-effluent treatment. Researchers used three renewable natural substrates that are widely available globally as agricultural residues, either free of cost or at a very low cost. Corn-cob shreds, wood-chips, and wheat-straw were used in experiments for their ability to adsorb individual dyes and mixture of dyes from solutions consisting of synthetic dyes commonly used in textile companies. Nine individual Ciba Geigy dyes were used: Cibacron Red C-2G-reactive dye, Remazol Navy Blue GG-diazo dye, Remazol Red RB-diazo dye, Cibacron Orange CG-reactive dye, Remazol Golden Yellow RNL-azo dye, Hisperse Navy D2GR-disperse dye, Remazol Blue B-diazo dye, Remazol Turquoise Blue G 133 -phthalocynine dye, and Remazol Black B-diazo dye. The textile effluent was simulated as a mixture of all nine dyes. These residual agricultural substrates were used for removing colour from dye-contaminated water instead of using chemicals in order to study them as an economical and eco-friendly method of bio-remediation. Researchers have reported that up to $70-75 \%$ colour removal was achieved using corncob shreds and wheat straw from solutions of $500 \mathrm{mg} / \mathrm{L}$ dye [6-8]. Increasing the temperature of the process to above room temperature for the adsorption of dyes had no appreciable effect on the adsorption capacity of both residues. Corncob was the most efficient in dye colour removal, whereas wood chips had no adsorption of dyes due to their lignin-containing complex structure.

There are other reports where researchers have used some locally/regionally available, low-cost, agricultural materials as biosorbents, such as residual apple pomace left after the juice extraction and 
wheat straw, for the removal of colour from a solution of textile dyes [9]. Experiments were performed with a synthetic effluent prepared in a lab, consisting of an equal mixture of five types of textile dyes at total dye concentrations of 10, 20, 30, 40, 50,100, 150, and $200 \mathrm{mg} / \mathrm{L}$ of solution. The factors studied by these workers included the effect of dye concentration in solution, particle size of agricultural residues used as bio-sorbent material, amount of biosorbent added in dye-solution, the rate of adsorbance, percentage of dye removal, and the application of isotherms of Langmuir and Freundlich. The results proved apple pomace to be a better material for colour adsorption, adsorbing $81 \%$ of dyes from the synthetic effluent when used in the form of $2 \times 4 \mathrm{~mm}$ particles. Even higher colour removal was achieved, up to $91 \%$, when using dried apple pomace in a fine powdered form containing $600-\mu \mathrm{m}$ particles. Apple pomace showed adsorption of dyes at a faster rate than the other substrate of wheat straw; the reason is that wheat-straw has less sorption power in its complex lignin-containing structure, and apple pomace has negligible lignin.

The use of these cheaply available substrates has been compared with the biosorption capacity of other commonly available agricultural residues, e.g., corncob and barley-husk [10]. The effectiveness of adsorption mechanism, as a method of colour removal, has made it an ideal alternative to other reported methods, which proved to be expensive treatments. Researchers conducted experiments in simulated effluents made of an equal amount of five commonly used textile dyes, setting the total dye concentrations in solution up to $200 \mathrm{mg} \mathrm{L}^{-1}$. Several parameters were studied for the optimisation of the process, including dye concentration in solution, size of agricultural residue-particles used as sorbent, dose of biosorbent added in solution, effective adsorbance of dyes on particles of solid substrates, and the kinetics of process of dye removal. Authors have reported that 10 grams (dry weight) of corncob of $\leq 600-\mu \mathrm{m}$ particle size used per $1000 \mathrm{~mL}$ solution of dyes was more effective in adsorption of a high percentage of colour in a shorter time $(92 \%$ reduction in colour of solution within $48 \mathrm{~h}$ of sorption process). The other substrate of barley husk used in the form of particle size $1 \times 4 \mathrm{~mm}$ was most effective in reference to the weight vs. particle size combination for the adsorption of dyes up to $92 \%$ in $48 \mathrm{~h}$. The results indicated both substrates, barley husk and corncob, could be used as economical and effective biosorbents for the removal of dyes from textile effluent $[8,10]$

\subsection{Optimisation of System Using Agricultural Residues}

\subsubsection{Pretreatment of Lignocellulosic Residues}

The agricultural residues are lignocellulosic in nature; their 20-25\% lignin content is a barrier in the effective use of cellulosic content. These residues can be effectively used for the sorption process after removing the lignin content from the substrates, making their cellulosic content freely-available for dye-sorption. The pretreatment of three agricultural residues, including barley husk, corncob, and wheat straw, were performed mainly for their delignification and to increase the surface area for the effective adsorption of coloured molecules by treated substrates [7]. A few commonly used pretreatment methods, mainly milling of large size material, steaming, alkali treatment, and ammonia-steeping, were tried and the performance of untreated and pretreated substrates was checked for their colour adsorption capabilities. The milled (powdered) samples removed a higher percentage of dye at a faster rate; therefore, milling of substrates to reduce particle size proved to be a better option for pretreatment of solid agricultural residual materials. Milling is also cost-effective and eco-friendly treatment process compared to steaming, alkali, or ammonia-steeping. The authors recommended the milling or grinding of substrates so no cost was calculated for chemical pretreatment methods. Three milled residues have been used in studies of adsorption process for colour removal from a solution of five commonly used dyes, which were obtained for experiments from a textile company (Remazol Black B, Cibacron Yellow C-2R, Cibacron Blue C-R, Cibacron Red C-2G, and Remazol Red RB) [7]. 


\subsubsection{Optimisation of Adsorption Conditions and Bio-Reactors}

A simple approach for the adsorption of textile dyes from the solution was studied by Chandran et al. [10]. The artificial dye-effluent was prepared by mixing two types of Clariant dyes, Solar Jade Green FFB and Solar orange 7 GLL, and the absorption of colour was studied onto particles of three commonly available agricultural residues, i.e., wheat straw, sugarcane bagasse, and barley husk. These agricultural residues particles of $600-\mu \mathrm{m}$ size were used as sorbent-material in solution at $20 \%$ concentration (dry weight, $w / v)$; each substrate was tested in a separate experiment. The dye removal could be clearly seen within all substrates when the effluent contained dye concentrations in the range of 50 to 200 $\mathrm{mg} / \mathrm{L}$. Dye-adsorption on substrates was performed and calculated using two main conditions at which actual effluent is generated in textile industries. The conditions studied in the adsorption system were the effect of temperature of the solution in range of 25 to $50{ }^{\circ} \mathrm{C}$ and $\mathrm{pH} 6.0$ to 12.0 [9].

The bioreactors were designed by Robinson et al. [11] for batch and continuous dye-adsorption onto solid residues. The researchers studied the adsorption of five reactive dyes present in a synthetic textile dye effluent on particles of barley husks in process-systems designed as a static batch-mode reactor and a packed-bed reactor (CFPBR) operating with a continuous flow of effluent, with the purpose of a large-volume of water treatment. Under static batch-mode conditions, the adsorption of dyes, initial concentrations $\left(C_{0}\right)$, and thermodynamics were studied, whereas, in CFPBR, the effect of $C_{0}$ and retention time $(\tau)$ were studied by changing the packed weight and the height of packing column, which could affect the kinetics of dye adsorption. The saturation capacities were predicted by Langmuir isotherm. In such experiments, barley husks removed $8 \mathrm{mg}$ dyes per $\mathrm{g}$ dry weight of barley husk at $C_{0} 100 \mathrm{mg} \mathrm{L}^{-1}$ in the reactor (CFPBR), with a column flow adjusted with a liquid-residence time of $11 \mathrm{~min}$. In such a set-up of the reactor, the authors achieved $90 \%$ adsorption of colour on particles of barley husk [12]. The safety of disposal of the biosorbant material after the biosorption-removal of dyes was studied, as described in the following sections.

\section{Use of Microbial Agents in Remediation System}

\subsection{White-Rot Fungi in Solid-State Cultivation}

The dye-adsorbed agricultural residues that resulted after the above dye-removal experiments needed safe disposal into the environment. Several experiments were conducted using dye-adsorbed material, and the researchers found that these dye-adsorbed substrates could be used in solid-state fermentation (SSF) cultivating two strains of white-rot fungi-Coriolus versicolor and Phanerochaete chrysosporium [12,13]. Both fungi grew well in the form of thick mycelial growth in SSF without any inhibition due to presence of dye chemicals and produced a fungal-biomass with a protein content of $19,23,50 \mathrm{~g}$ and 16, 25, $35 \mathrm{~g}$, respectively, per $100 \mathrm{~g}$ dry weight of three substrates used in SSF: wood chips, corncob shreds, and wheat straw (Figures 1 and 2).

Robinson and Nigam, [13] followed a strict screening strategy for the selection of most effective microorganism for dye-degradation employing few white-rot fungi in SSF. The process was studied for the treatment of an actual effluent generated from one Ireland-based American textile industry. After the screening process, one fungus, Bjerkandera adusta, was investigated in detail for its ability to grow on solid substrate adsorbed with dye-molecules. Fungal mycelium produced in solid-state fermentation enriched the nutritional quality of residual barley husks. Project work included the detailed study of important parameters, including SSF-medium composition, requirements of moisture, enzymes produced by fungi during SSF, and the protein content in fermented barley husk covered with fungal mycelium biomass. Experiments were further conducted to optimise the protein-enrichment of SSF material by supplementing the process with nitrogen at a 20:1 C:N ratio [14]. This approach provided preliminary findings and suggestions for the treatment of textile effluent, and the bioconversion of utilised agricultural substrates as dye-adsorbed material into protein-enriched mass after fungal growth for their safe recycling as a soil conditioner when mixed with soil. 


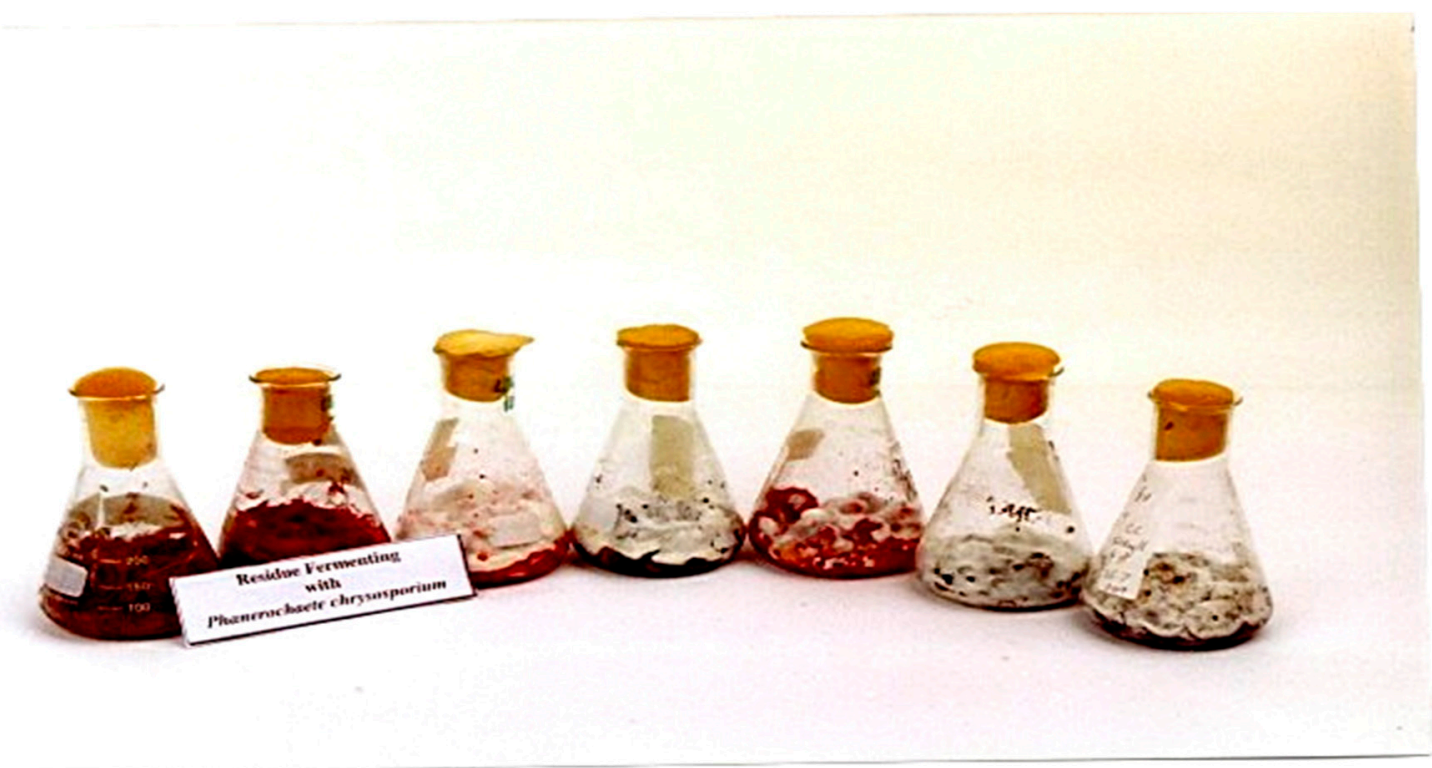

Figure 1. Recycling of agricultural residual material for textile dyes-removal from wastewater, and bioremediation using bioagents. (Picture taken by author P. Nigam from lab experiment, not published anywhere).
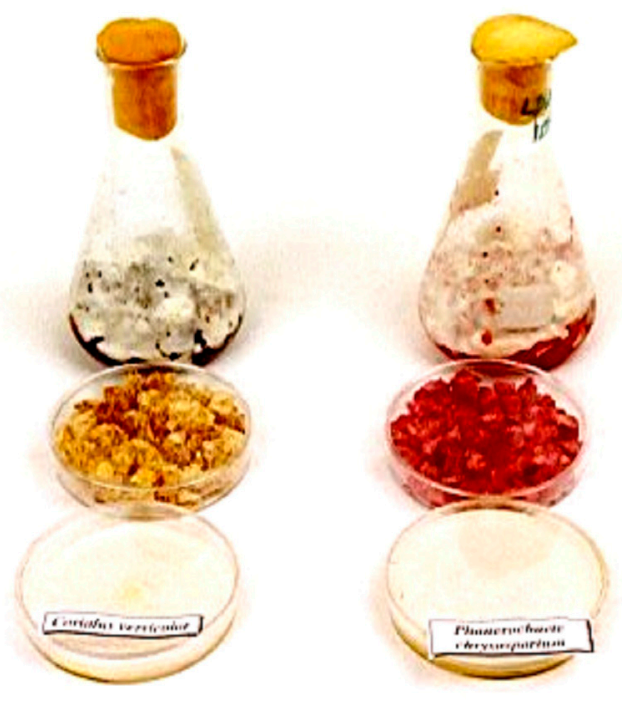

Figure 2. Growth of two white-rot fungi Phanerochaete chrysosporium and Coriolus versicolor in the fermentation of dye-adsorbed substrates. (Picture taken by author P. Nigam from lab experiment, not published anywhere).

A method, which was previously optimised [15] for the extent of dye desorption from dye-adsorbed solid particles, was used to measure the degradation of dyes as a result of fungal enzyme activity during the period of SSF. Using this method, fungal strain B. adusta was reported to decolourise the synthetic dye up to $53 \%$ in SSF performed at a moisture content of $80-85 \%$. The fermented mass due to fungal-growth was enriched with protein and analysed as $229 \mathrm{~g} / \mathrm{kg}$ dry weight of substrate used in fermentation. After SSF, the fermented mass of dye-adsorbed residues was analysed for actual dyes degradation by fungi and content of dyes still left adsorbed on fermented substrates. There was no standard method for the quantitative analyses of dyes contained in solid agricultural substrates after microbial degradation; therefore, researchers [15] studied the extraction of colour from SSF-material, which could be analysed quantitatively. Two types of preparation of solvents-A consisted of methanol + chloroform + water in equal ratio; B consisted of 1:1 methanol and water-were tested to wash 
out the dyes adsorbed onto substrates' particles. This method was optimised for the analyses of the percentage of dyes degraded during fungal growth in SSF.

Apple pomace, barley husk, and corncob were soaked separately in individual solutions of five separate dyes, and in a synthetic textile-effluent prepared by mixing equal ratio of all five dyes, which were used for the adsorption of dyes on substrates' particles. Two preparations of solvents named as A and $\mathrm{B}$ were used for the extraction or desorption of colour from these dye-adsorbed substrates. Using solvent A, the maximum level of $93 \%$ desorption of Cibacron Red from corncob was achieved. The most effective substrate was barley husk, from which $82 \%$ the synthetic textile effluent could be desorbed using solvent A. This method was applied as an approximate calculation of dyes degradation in SSF [15] in solutions of dyes extracted/desorbed from dye-adsorbed material using solvents, before and after SSF by fungal growth.

\subsection{Bacterial Cultures in Submerged Fermentations}

The capability of some bacteria to decolourise and metabolise dyes is known, and therefore the use of remediation technology using these microbes has attracted the interest of many researchers for the biological-treatment of textile wastewater. A group of researchers [3] have studied microbiological decolourisation of dyes from textile industries and reported on its benefits and limitations. Other group [4] reviewed the mechanisms of degradation of dyes used by diverse groups of microorganisms, including anaerobic bacteria consortia. The employment of bacteria for their ability to carry out dye decolourisation has been studied in detail [2-4]. The research work has revealed the isolation of a variety of microorganisms capable of decolourising a wide range of synthetic dyes. Microbial degradation and decolourisation of dyes is beneficial, being a chemical-free method for the removal of these chemicals from the water sources.

A practical and simple biological process using bacteria for the decolourisation of coloured wastewater obtained from a textile company has been studied by Nigam et al. [16-18]. Few aerobic and anaerobic microbes were isolated, showing their capability to decolourise dyes present in textile effluent samples, after prolonged enrichment-culturing of samples collected from textile industry. The decolourisation of some dyes of the effluent and of a solution made in a lab with a mixture of dyes was only observed under anaerobic conditions, suggesting that the chromophoric bonds in the dye structure were broken by bacteria. The five anaerobic bacterial isolates (named as PDC 1 to 5) capable of complete decolourisation of some dyes in individual-dye solutions were further examined in liquid fermentation under anaerobic conditions. One bacterial isolate was capable of decolourising Remazol-Red (diazo dye), Cibacron-red (reactive dye), and Remazol-Golden Yellow (azo dye) completely within one day $(24-30 \mathrm{~h})$ of the fermentation process. It also decolourised a reactive dye, Cibacron-Orange, and a diazo dye, Remazol Navy Blue, within 48 h; Remazol-Blue was decolourised within $54 \mathrm{~h}$.

The researchers have reported that the decolourisation of these dyes was permanent with no revert or change in the colour of the medium on exposure to oxygen. However, a phthalocyanine dye, Remazol-Turquoise Blue, was first completely decolourised but its original colour partially reversed after the exposure of the fermented medium to air. The possible applications of these bacterial isolates in decolourisation and treatment of textile dye effluent have been discussed in a few publications [16-18].

A microbial consortium named as PDW, isolated from dye-contaminated soil samples collected from a textile company, was studied in detail [17]. This consortium was found capable of the fast decolourisation of commercial textile dyes in a process performed under anaerobic conditions. Decolourisation was affected by the presence of another carbon source in the medium containing textile dyes. This bacterial consortium was found efficient in dye decolourisation when growing in dye-solutions supplemented with low-cost and readily available industrial byproducts used as carbon sources, including lactose-whey, distillery-waste, and starch. PDW reduced colour from textile plant effluent up to $76 \%$ in 3 days [17]. Bacterial culture was grown in simulated effluent (mixture of nine dyes, total concentration of dyes $0.5 \mathrm{~g} / \mathrm{L}$ or $500 \mathrm{mg} / \mathrm{L}$ ), and with individual dye components at the same concentration of $0.5 \mathrm{~g} / \mathrm{L}$, separately. Bacteria could grow at $0.5 \mathrm{~g} / \mathrm{L}$ dye concentration, which is a very dark coloured solution compared to dye concentration in water bodies after the disposal of actual dye effluent. So if bacteria could remove 
$76 \%$ of colour at $0.5 \mathrm{~g}$ or $500 \mathrm{mg} / \mathrm{L}$ dye solutions, these could be applied to much-diluted solution of dyes $(0.1,0.2 \mathrm{~g} / \mathrm{L})$ for a higher percentage of dye removal, fulfilling the environmental regulations.

For large volumes of textile water remediation, microbial fermentation performed in batch conditions for 5-6 days is not a practical and economical option; hence, a continuous treatment system should be in operation to deal with vast volumes generated in textile industries. For this purpose, researchers have experimented on immobilising bacterial cultures in a biofilm system for their long-term application in a continuous-flow decolourisation process [18]. Some cheaply available materials, such as solidified highly porous volcanic lava called Kissiris obtained from Greece, seashells, sponge-scrubbers, and nylon-webs, were used to grow biofilms of individual bacteria and bacterial-consortium with capabilities of textile-effluent decolourisation. These biofilm-containing support systems were studied for their efficiency in the decolourisation in a continuous-flow packed-bed-column bioreactor (CFPBR) system. Biofilm support systems using volcanic mineral material, nylon-web, and seashells supported good bacterial growth in the form of actively growing bio-films. These bio-systems were established to decolourise textile effluent, without the release of a noticeable number of bacterial-cells released from biofilm attached to the substratum into the outflow of treated effluent $[17,18]$. Therefore, a continuous process for effluent treatment could be performed for a longer period treating a larger volume of effluent compared to a batch treatment process. The effluent generated by textile companies is high in temperature; therefore, Banat et al. [19] studied the isolation of thermophilic bacterial strains capable of growing and decolourising textile dyes present in effluents at higher temperatures.

\subsection{Use of Other Microorganisms (Yeast and Fungi)}

The ability of a thermo-tolerant strain of yeast Kluyveromyces marxianus has been investigated by Meehan et al. [20] to decolourise a commonly used textile dye, Remazol-BlackB. The effect of important culture conditions, e.g., of $\mathrm{pH}$ and temperature, were studied. No appreciable effect on decolourisation was seen in a $\mathrm{pH}$ range of 3.0-5.5. Maximum colour removal up to $98 \%$, was achieved when yeast grew at $37^{\circ} \mathrm{C}$. No colour removal was observed in the experiment of $\mathrm{K}$. marxianus grown under anaerobic cultivation conditions. Further studies for decolourisation were conducted under conditions of extreme temperature and lower $\mathrm{pH}$ (to inhibit the yeast growth and to study the role of yeast in decolourisation). When using ten times concentrated yeast inoculum, the results proved that the decolourisation of medium appeared by adsorption of colour onto the yeast cells; no metabolic reaction happened in the breaking down of dye molecules [20].

Few fungi also have been studied for their ability to break down five different textile-dyes when mixed together in an artificial lab-made dye-effluent. The experiments were performed using Coriolopsis gallica and Phanerochaete chrysosporium in nitrogen-rich medium at C:N ratio set at 11.6:1, and in nitrogen-limited medium at C:N ratio set at 116:1 [14]. P. chrysosporium showed 53.6\% decolourisation of the effluent in $\mathrm{N}$-rich medium and a bit lower at $48 \%$ in a medium of limited $\mathrm{N}$. However, in another fungal culture of C. gallica, the decolourisation capability was higher, up to $86.9 \%$ in N-limited and $80.7 \%$ in N-rich medium. The supplementation of nitrogen helped in the stimulation of enzyme activities, and, as a result, dye decolourisation was improved for P. chrysosporium. However, the increasing nitrogen level stimulated enzyme production in C. gallica without any improvement in the rate of decolourisation. These results highlighted the possible use of fungal cultures for the treatment of dye effluent.

During ongoing experiments for a search of effective microorganisms capable of degrading synthetic dyes in effluents, a filamentous fungi growing under facultative anaerobic condition was isolated from a vessel containing dyes-effluent stored for a longer period [21]. This fungi showed the ability to grow on dyes as the sole source of carbon when cultivated under two different conditions, aerobic and anaerobic. This fungal isolate grew in the form of a thick mycelial mat in dye-containing medium, but no decolourisation of the medium was observed, indicating that the fungus did not produce required enzymes to break the azo-bond present in dye molecules, though it metabolised other parts in dye structure to support its thick mycelial growth. 
The evidence for the use of dyes by fungus for its growth came from the physical examination of fermented medium in comparison with the control mycelium-free dye-supplemented growth medium. This was confirmed analytically using capillary electrophoresis and UV-vis spectrophotometry. The analysis showed that though the dye solution was not decolourised, but results showed changes in the UV-vis spectra. The results were indicative of degradative-changes, which occurred in the parts of dye molecules other than on their chromophoric centres. The authors concluded from the study of the degraded dyes by capillary-electrophoresis that the thick mycelial growth of fungus induced the structural changes in dyes [21].

\section{Enzymes Involved in Dye Degradation}

A group of lignin-containing plant-residue-decaying microorganisms has been classified in class basidiomycetes as white-rot fungi. These fungi have capability to degrade lignin molecules present in the complex polymers into carbon dioxide and water. The fungal metabolism produces several extracellular enzymes, which have been studied for their activities in the degradation of lignin and lignin-type molecules. These enzymes are reported to be heme peroxidases, such as manganese peroxidase (MnP), versatile peroxidase (VP), lignin peroxidase (LiP), and laccase (Lac) [22-24]. Dye-decolourising peroxidase $(\mathrm{DyP})$ is a member of the novel heme peroxidase family (DyP-type peroxidase superfamily), showing no homology to fungal heme peroxidases-MnP, VP, and LiP $[25,26]$. Laccase and lignin peroxidase have been identified to be two main enzymes in solid-state fermentation performed with dye-adsorbed substrates [12]. Four different white-rot cultures, including Bjerkandera adusta, Coriolus versicolor, Pleurotus ostreatus, and Phlebia tremellosa were grown in SSF to synthesise enzymes responsible for lignocellulosic and similar structure-containing materials. Three types of enzymes, laccase, lignin-peroxidase (LiP), and manganese-peroxidase $(\mathrm{MnP})$, were produced in a mineral salt medium that was nitrogen-deficient. P. tremellosa and B. adusta produced high enzyme activities and performed better in the decolourisation of an artificial effluent consisting of five different dyes. Degradation studies were performed at a higher C:N ratio of 11.6:1 and under an N-limited condition (C:N ratio of 116:1) in a medium with $100 \mathrm{mg} / \mathrm{L}$ dye. Cultivation of B. adusta for 7 days in N-rich medium decolourised dyes to $85 \%$, and P. tremellosa decolourised dyes up to $79 \%$ in 9 days. In contrast, under $\mathrm{N}$-limited conditions, $86 \%$ of the effluent was decolourised by B. adusta in 9 days, and $74 \%$ decolourisation was shown in the medium of $P$. tremellosa after 11 days. Supplementation of nitrogen showed no effect on percentage dye decolourisation by B. adusta, though only a slight increase was noticed in P. tremellosa. However, the decolourisation time was reduced by nitrogen supplementation. These results indicated the potential of $P$. tremellos $a$ and $B$. adusta for textile-effluent treatment [13].

Some strains of microorganisms are reported for their activity in the decolourisation of textile dyes as they are capable of producing a specific enzyme complex [26]. Such capability was explored in a different scenario in the textile industry by Chatha et al. [27]. The problem of faulty dyeing due to uneven colouring often occurs in the finished fabrics in the textile industry. This uneven extra colouring is usually removed through a process called chemical-stripping, which helps in removing the loose dyes from cotton fabrics. A research project was undertaken to study the stripping of colour from cotton-fabrics dyed with a synthetic dye, C.I. reactive black 5 , in an environment-friendly effort using microbial-enzymes instead of using the method of stripping by synthetic chemicals. The microbial enzymes were prepared by cultivating a white-rot fungus, Ganoderma lucidum, in solid-state fermentation (SSF), applying optimised conditions. Crude preparations of SSF-enzyme extract were used in the biological colour-stripping process.

The enzymes produced in culture extract from the fermentation of white-rot fungus G. lucidum, were analysed as laccase (EC1.10.3.2) with the activity of $68 \mathrm{U} / \mathrm{mL}$, lignin peroxidase (EC1.11.1.14) with the activity $530 \mathrm{U} / \mathrm{mL}$, and manganese peroxidase (EC1.11.1.13) with the activity of $395 \mathrm{U} / \mathrm{mL}$. Important parameters to achieve effective colour-stripping were studied, such as enzyme activity (units) present in SSF-extracted filtrate, the conditions of enzyme reaction such as duration of enzyme contact with the coloured fabric, $\mathrm{pH}$, and temperature. The colour-stripping efficiency using the enzyme-catalysed process was measured in the treated fabric as K/S values, before and after the 
enzymatic colour removal [27]. In this study, culture filtrate extracted from solid-state fermentation was used without any purification process as a crude preparation of enzyme. This source of enzymes consisted of appreciable units of laccase, lignin peroxidase, and manganese peroxidase activities. Using crude extract as a cheaper enzyme preparation in an optimised process, up to $71 \%$ of colour-stripping of uneven-dyed fabric could be achieved. There are reports for using crude enzyme extracts for dye decolourisation [28]. In contrast, in other reports, purified and specifically characterised preparation of enzymes were used for dye decolourisation and hydrolysis of straw $[29,30]$. Our approach of using crude inexpensive enzyme preparation is not only safer to use on fabrics but also environment-friendly for colour-stripping in the textile industry, in comparison to chemical methods that could be damaging if used on cotton fabric.

\section{Toxicity of Dye Effluents}

The textile dyes are highly toxic and potentially carcinogenic [31], causing damage to the environment and various diseases in animals and humans [32]. Bioremediation refers to the use of microbial systems to reduce, if not completely eliminate, the concentrations of toxic wastes, which could be hazardous to the ecosystem. The detoxification of coloured chemicals is anticipated to reduce the toxicity of these compounds. The main objective should be zero emission of colour, as well as the removal of toxic compounds through the discharge of treated textile effluent into the environment. The reason why this is so important is the enzymatic breakdown reactions in the microbial decolourization process produces colourless products that could be even more toxic than the actual colouring chemicals [33].

The toxicity in effluents is mainly due to the formation of dye metabolites. Azo dyes are composed of aromatic amines, substituted benzene, and naphthalene rings, which have been identified as potentially carcinogenic molecules. Although most of azo dyes are non-toxic, in the treatment process, the breakdown compounds produced have been found to be toxic. Many textile effluents may also contain heavy metals that can be structurally complexed in azo dyes. The breakdown mechanism contributing to the toxicity of azo dye-compounds could be due to several reasons. Either azo dyes become toxic only after the cleavage of the azo bond, resulting in their reduction to aromatic amines, or some azo dyes containing free aromatic amine groups can be metabolically-oxidised without azo reduction, or, following the direct oxidation of the azo linkage present in azo dye, toxic activation takes place due to the production of electrophilic diazonium salts. The textile industry effluents are recalcitrant to biodegradation due to the presence of various types of dyes, and in this way, they cause toxicity to water-sources. Therefore, the decolourisation and detoxification of textile wastewater are very important to degrade the toxic chemicals present in textile wastewater before releasing it into waterbodies [31-33].

\section{Toxicity Tests}

The wastewater generated from the textile industries after treatment is generally released into water resources for irrigation of agricultural lands. Therefore, it is obligatory to test the toxicity of textile effluents before and after treatment on the crop-seeds. For this purpose, the usual methods to study phytotoxicity are through the monitoring of germination of crop-seeds and, later, the growth of seedlings into plants. These studies are important to assess the toxic nature of dye molecules released into irrigation water. Pourbabaee et al. [34] studied the germination of three plant seeds irrigated with untreated and treated textile wastewater. A 100\% inhibition in seeds germination was noticed in Lens orientalis and 50-60\% in Triticum boeoticum with the use of untreated effluent at $30 \mathrm{ppm}$, while $100 \%$ inhibition occurred at 50-150 ppm in T. boeoticum. The least sensitive seeds were from Triticum aestivum, which showed $30 \%$ and $50 \%$ inhibition at 30 and $50-150 \mathrm{ppm}$, respectively. In the study of bacterial bioremediation employing Bacillus sp., after the treatment process, the effluent was $100 \%$ decolourised and found less toxic, showing $10 \%$ inhibition in T. boeoticum seeds and $0.0 \%$ on L. orientalis and T. aestivum seeds. This toxicity test resulted in the assumption that due to the consumption of biodegradation products formed by Bacillus sp. or transformation to non-toxic metabolites, the germination of seeds was not adversely affected. 
Liao et al. [35] have studied the toxic effects of an azo dye, Reactive Black B (RBB), on the cultivation of a freshwater algae Chlorella vulgaris, which is a microalgae mainly used as a dietary supplement or protein-rich food additive. The studies showed that a growth medium containing azo dye RBB was toxic for the growth of algae toxicity with $\mathrm{EC}_{50}$ calculated as $48 \mathrm{mg} \mathrm{L}^{-1}$. Kabra et al. [36] have studied the toxicity effect of untreated and treated dye mixture and textile effluent using a bacterial consortium (Glandularia pulchella+Pseudomonas monteilii ANK) on germination and growth of seeds of two crops, Phaseolus mungo and Sorghum vulgare. The outcome of their experiment showed a higher percentage of seeds germination in experimental-sets irrigated with distilled water and treated textile effluents and treated dye mixture, whereas the growth of seedlings was inhibited in sets of untreated effluents and dye mixture. This study confirmed the toxicity of untreated dyes wastewater, while the treated samples produced similar results for the germination of seeds as with the use of distilled water.

In comparison to bacterial treatment for dye colour removal, the fungal treatment of textile dyes is an economical and effective alternative for bioremediation. The main mechanisms involved are biosorption, bioaccumulation, and biodegradation [37]. Therefore, myco-remediation is a natural and low-cost process [38]. In this case, endophytic biodegradation occurs because of the activity of fungal enzymes, laccase, lignin peroxidase, Mn peroxidase, reductase, and tyrosinase [39]. Moreover, the breakdown process takes place in a confined environment as in soil-conditioning and composting, as compared to the discharge of toxic effluents and treated effluents into water resources after bacterial treatment in liquid systems $[4,12,13]$.

\section{Conclusions and Future Perspective}

Several researchers have suggested different processes and technologies for the remediation of textile wastewater [40-43]; most of them have employed microbial agents, including bacterial and fungal species, from a variety of sources [44]. Agricultural residual materials have complex structures with high strength, environmentally friendly nature, low cost, and global availability. A few important agro-waste products, which are suitable for reducing chemical contaminants in water, have been reviewed for their applicability for remediation of chemical contaminants in water systems [45]. A review of the above research suggests that cheaply available agricultural residues are available globally as low-cost materials, which could be used for two purposes: Firstly, their economic and safe recycling to comply with a re-use strategy for environmental protection, and secondly, for the reduction of colour in textile wastewater. The renewable sources of agricultural residues such as wheat-straw, corncob and barley-husk are cheaper materials for the cultivation of microorganisms such as mycelial-fungi for the biosynthesis of enzymes active in the breakdown of dye-molecules. The crude enzyme preparations of microbial cultivations in solid-state fermentation were found to be rich in three types of enzyme activities, which could be used without any expensive purification process, as biodegradable chemicals (instead of toxic chemicals) for colour-stripping from unevenly dyed fabrics in the textile industry.

Author Contributions: D.D. has reviewed the literature, collected relevant references from published articles and prepared first draft. author P.S.N. has added more information, references, pictures of lab-scale experiments and submitted final version of this review article. All authors have read and agreed to the published version of the manuscript.

Funding: This work involved no experimental labwork and therefore, received no external funding

Acknowledgments: There is no research grant used in compiling of this review article.

Conflicts of Interest: None, as this is a review of literature, and contains no data, all information presented in articles has been supported with relevant references.

\section{References}

1. Lellis, B.; Fávaro-Polonio, C.Z.; Pamphile, J.A.; Polonio, J.S. Effects of textile dyes on health and the environment and bioremediation potential of living organisms. Biotechnol. Res. Innov. 2019, 3, $275-290$. [CrossRef]

2. Banat, I.M.; Nigam, P.; Singh, D.; Marchant, R. Microbial decolorization of textile-dye-containing effluents: A review. Bioresour. Technol. 1996, 58, 217-227. [CrossRef] 
3. McMullan, G.; Meehan, C.; Conneely, A.; Kirby, N.; Robinson, T.; Nigam, P.; Banat, I.; Marchant, R.; Swyth, W.F. Microbial decolourisation and degradation of textile dyes. Appl. Microbiol. Biotechnol. 2001, 56, 81-87. [CrossRef]

4. Robinson, T.; McMullan, G.; Marchant, R.; Nigam, P. Remediation of dyes in textile effluent: A critical review on current treatment technologies with a proposed alternative. Bioresour. Technol. 2001, 77, 247-255. [CrossRef]

5. Hassan, M.M.; Carr, C.M. A critical review on recent advancements of the removal of reactive dyes from dye house effluent by ion-exchange adsorbents. Chemosphere 2018, 209, 201-219. [CrossRef]

6. Nigam, P.; Robinson, T.; Singh, D. A critical review on remediation technologies of textile effluents. In Green Chemistry-Environment Friendly Alternatives; Sanghi, R., Srivastava, M.M., Eds.; Narosa Publishing: New Delhi, India, 2003; pp. 260-277, ISBN 81-7319-523-4.

7. Robinson, T.; Chandran, B.; Nigam, P. Effect of pretreatments of three waste residues, wheat straw, corncobs and barley husks on dye adsorption. Bioresour. Technol. 2002, 85, 119-124. [CrossRef]

8. Robinson, T.; Chandran, B.; Nigam, P. Removal of dyes from an artificial textile dye effluent by two agricultural waste residues, corncob and barley husk. Environ. Int. 2002, 28, 29-33. [CrossRef]

9. Robinson, T.; Chandran, B.; Nigam, P. Removal of dyes from a synthetic textile dye effluent by biosorption on apple pomace and wheat straw. Water Res. 2002, 36, 2824-2830. [CrossRef]

10. Chandran, C.B.; Singh, D.; Nigam, P. Remediation of textile effluent using agricultural residues. Appl. Biochem. Biotechnol. 2002, 102, 207-212. [CrossRef]

11. Robinson, T.; Chandran, B.; Naidu, G.S.; Nigam, P. Studies on the removal of dyes from a synthetic textile effluent using barley husk in static-batch mode and in a continuous flow, packed-bed, reactor. Bioresour. Technol. 2002, 85, 43-49. [CrossRef]

12. Nigam, P.; Armour, G.; Banat, I.M.; Singh, D.; Marchant, R. Physical removal of textile dyes from effluents and solid-state fermentation of dye-adsorbed agricultural residues. Bioresour. Technol. 2000, 72, 219-226. [CrossRef]

13. Robinson, T.; Nigam, P. Remediation of textile dye-waste water using a white rot fungus Bjerkandera adusta through solid-state fermentation (SSF). Appl. Biochem. Biotechnol. 2008, 151, 618-628. [CrossRef]

14. Robinson, T.; Chandran, B.; Nigam, P. Studies on the decolourisation of an artificial textile-effluent by white-rot fungi in N-rich and N-limited media. Appl. Microbiol. Biotechnol. 2001, 57, 810-813. [CrossRef]

15. Robinson, T.; Chandran, B.; Nigam, P. Studies on desorption of individual textile dyes and a synthetic dye effluent from dye-adsorbed agricultural residues using solvents. Bioresour. Technol. 2002, 84, 299-301. [CrossRef]

16. Nigam, P.; Banat, I.M.; Singh, D.; Marchant, R. Microbial process for the decolorization of textile effluent containing azo, diazo and reactive dyes. Process. Biochem. 1996, 31, 435-442. [CrossRef]

17. Nigam, P.; McMullan, G.; Banat, I.M.; Marchant, R. Decolourisation of effluent from the textile industry by a microbial consortium. Biotechnol. Lett. 1996, 18, 117-120. [CrossRef]

18. Nigam, P.; Marchant, R. Selection of a substratum for composing biofilm system of a textile-effluent decolorizing bacteria. Biotechnol. Lett. 1995, 17, 993-996. [CrossRef]

19. Banat, I.M.; Nigam, P.; McMullan, G.; Marchant, R.; Singh, D. The isolation of thermophilic bacterial cultures capable of textile dyes decolorization. Environ. Interl. 1997, 23, 547-551. [CrossRef]

20. Meehan, C.; Banat, I.M.; McMullan, G.; Nigam, P.; Smyth, F.; Marchant, R. Decolorization of Remazol Black-B using a thermotolerant yeast, Kluyveromyces marxianus IMB3. Environ. Inter. 2000, 26, 75-79. [CrossRef]

21. Nigam, P.; Banat, I.M.; Oxspring, D.; Marchant, R.; Singh, D.; Smyth, W.F. A new facultative anaerobic filamentous fungus capable of growth on recalcitrant textile dyes as sole carbon source. Microbios 1995, 84, 171-185.

22. Robinson, T.; Chandran, B.; Nigam, P. Studies on the production of enzymes by white-rot fungi for the decolourisation of textile dyes. Enz. Microb. Technol. 2001, 29, 575-579. [CrossRef]

23. Qin, X.; Luo, H.; Zhang, X.; Yao, B.; Ma, F.; Su, X. Dye-decolorizing peroxidases in Irpex lacteus combining the catalytic properties of heme peroxidases and laccase play important roles in ligninolytic system. Biotechnol. Biofuels 2018, 11, 302. [CrossRef] [PubMed]

24. Liers, C.; Pecyna, M.J.; Kellner, H.; Worrich, A.; Zorn, H.; Steffen, K.T.; Hofrichter, M.; Ullrich, R. Substrate oxidation by dye-decolorizing peroxidases (DyPs) from wood-and litter-degrading agaricomycetes compared to other fungal and plant heme-peroxidases. Appl. Microbiol. Biotechnol. 2013, 97, 5839-5849. [CrossRef] [PubMed] 
25. Hofrichter, M.; Ullrich, R.; Pecyna, M.J.; Liers, C.; Lundell, T. New and classic families of secreted fungal heme peroxidases. Appl. Microbiol. Biotechnol. 2010, 87, 871-897. [CrossRef]

26. Fernandez-Fueyo, E.; Linde, D.; Almendral, D.; Lopez-Lucendo, M.F.; Ruiz-Duenas, F.J.; Martinez, A.T. Description of the first fungal dye-decolorizing peroxidase oxidizing manganese (II). Appl. Microbiol. Biotechnol. 2015, 99, 8927-8942. [CrossRef]

27. Chatha, S.A.S.; Mallhi, A.I.; Hussain, A.I.; Asgher, M.; Nigam, P.S. A Biological Approach for Colour-Stripping of Cotton Fabric Dyed with C.I. Reactive Black 5 Using Fungal Enzymes from Solid State Fermentation. Curr. Biotechnol. 2014, 3, 166-173. [CrossRef]

28. Oliveira, S.F.; da Luz, J.M.R.; Kasuya, M.C.M.; Ladeira, L.O.; Junior, A.C. Enzymatic extract containing lignin peroxidase immobilized on carbon nanotubes: Potential biocatalyst in dye decolourization. Saudi J. Biol. Sci. 2018, 25, 651-659. [CrossRef]

29. Qin, X.; Zhang, J.; Zhang, X.; Yang, Y. Induction, purification and characterization of a novel manganese peroxidase from Irpex lacteus CD2 and its application in the decolorization of different types of dye. PLoS ONE 2014, 9, e113282. [CrossRef]

30. Salvachúa, D.; Prieto, A.; Martínez, Á.T.; Martínez, M.J. Characterization of a novel dye-decolorizing peroxidase (DyP)-type enzyme from Irpex lacteus and its application in enzymatic hydrolysis of wheat straw. Appl. Environ. Microbiol. 2013, 79, 4316-4324. [CrossRef]

31. Sharma, B.; Dangi, A.K.; Shukla, P. Contemporary enzyme based technologies for bioremediation: A review. J. Environ. Manag. 2018, 210, 10-22. [CrossRef]

32. Khan, S.; Malik, A. Toxicity evaluation of textile effluents and role of native soil bacterium in biodegradation of a textile dye. Environ. Sci. Pollut. Res. Int. 2018, 25, 4446-4458. [CrossRef] [PubMed]

33. Garg, S.K.; Tripathi, M. Microbial Strategies for Discoloration and Detoxification of Azo Dyes from Textile Effluents. Res. J. Microbiol. 2017, 12, 1-19. [CrossRef]

34. Pourbabaee, A.A.; Malekzadeh, F.; Sarbolouki, M.N.; Najafi, F. Aerobic decolorization and detoxification of a disperse dye in textile effluent by a new isolate of Bacillus sp. Biotechnol. Bioeng. 2006, 93, 631-635. [CrossRef] [PubMed]

35. Liao, C.S.; Hung, C.H.; Chao, S.L. Decolorization of azo dye reactive black B by Bacillus cereus strain HJ-1. Chemosphere 2013, 90, 2109-2114. [CrossRef]

36. Kabra, A.N.; Khandare, R.V.; Govindwar, S.P. Development of a bioreactor for remediation of textile effluent and dye mixture: A plant-bacterial synergistic strategy. Water Res. 2013, 47, 1035-1048. [CrossRef]

37. Kaushik, P.; Malik, A. Mycoremediation of synthetic dyes: An insight into the mechanism, process optimization and reactor design. In Microbial Degradation of Synthetic Dyes in Wastewaters; Singh, S.N., Ed.; Springer: Berlin/ Heidelberg, Germany, 2015; pp. 1-25.

38. Jain, A.; Yadav, S.; Nigam, V.K.; Sharma, S.R. Fungal-mediated solid waste management: A review. In Mycoremediation and Environmental Sustainability; Prasad, R., Ed.; Springer: Berlin/Heidelberg, Germany, 2017; pp. 153-170.

39. Sim, C.S.F.; Chen, S.H.; Ting, A.S.Y. Endophytes: Emerging tools for the bioremediation of pollutants. In Emerging and Eco-Friendly Approaches for Waste Management; Bharagava, R.N., Chowdhary, P., Eds.; Springer: Singapore, 2019; pp. 189-217.

40. Gulzar, T.; Huma, T.; Jalal, F.; Iqbal, S.; Abrar, S.; Kiran, S.; Nosheen, S.; Hussain, W.; Rafique, M.A. Bioremediation of Synthetic and Industrial Effluents by Aspergillus niger Isolated from Contaminated Soil Following a Sequential Strategy. Molecules 2017, 22, 2244. [CrossRef]

41. Kiran, S.; Adeel, S.; Nosheen, S.; Hassan, A.; Usman, M.; Rafique, M.A. Recent trends in textile effluent treatments: A review. Adv. Mater. Wastewater Treat. 2017, 29, 29-49.

42. Meerbergen, K.; Crauwels, S.; Willems, K.A.; Dewil, R.; Van Impe, J.; Appels, L.; Lievens, B. Decolorization of reactive azo dyes using a sequential chemical and activated sludge treatment. J. Biosci. Bioengng. 2017, 124, 668-673. [CrossRef]

43. Ajao, A.T.; Adebayo, G.B.; Yakubu, S.E. Bioremediation of textile industrial effluent using mixed culture of Pseudomonas aeruginosa and Bacillus subtilis immobilized on agar agar in a bioreactor. J. Microbiol. Biotechnol. Res. 2017, 1, 50-56. 
44. Vikrant, K.; Giri, B.S.; Raza, N.; Kim, K.H.; Rai, B.N.; Singh, R.S. Recent advancements in bioremediation of dye: Current status and challenges. Bioresour. Technol. 2018, 253, 355-367. [CrossRef]

45. Sivaperumal, P.; Kannan, K.; Thilagaraj, W.R.; Gopalakrishnan, C.; Rajaram, R. Applicability of Agro Waste for Remediation of Chemical Contaminants in Water. Chapter 19. In Byproducts from Agriculture and Fisheries Adding Value for Food, Feed, Pharma, and Fuels; Simpson, B.K., Aryee, A.N.A., Toldrá, F., Eds.; John Wiley and Sons Ltd.: Hoboken, NJ, USA, 2019. [CrossRef] 